\title{
To Study the Effect of Austempering Temperature on Fracture Behaviour of Ni-Mo Austempered Ductile Iron (ADI)
}

\author{
Vikas Chawla $^{1 *}$, Uma Batra ${ }^{2}$, D. Puri ${ }^{3}$, Amita Chawla ${ }^{4}$ \\ ${ }^{1}$ Mechanical Engineering Department, L.L.R.I.E.T, Moga, Punjab, India \\ ${ }^{2}$ Metallurgy Department, P.E.C, Chandigarh, India \\ ${ }^{3}$ Metallurgical \& Materials Engineering, I.I.T. Roorkee, India \\ ${ }^{4}$ Chemistry Department, Govt. Brijindra College. Faridkot, Punjab, India \\ *Corresponding author: E-mail: edwalesir@rediff.com, \\ Phone: +91-9719749154, Fax: +91-1332-285243
}

\begin{abstract}
Austempered Ductile Iron (ADI) can be as twice as strong as standard spheroidal iron at the same level of toughness. It responds to work-hardening surface treatments and exhibits excellent fatigue and wear property. There is extensive work done on the fracture of steel with ferrite or/and austenite structure, but little on fracture behaviour of ADI whose microstructure also comprises austenite and ferrite but with graphite nodules in the matrix. The present work is aimed in this direction. The fracture behavior of Ni-Mo ADI is studied. It is found that the crack always originates from graphite nodules and the matrix affects the propagation path.
\end{abstract}

Keywords: Austempered ductile iron (ADI), Fractography, Dimpled structure, Fracture, Fracture mode.

\section{INTRODUCTION}

Austempered Ductile Iron (ADI) has 'come of age' during its brief history. ADI production is expected to grow at an annual rate of at least 5\% [1]. The microstructure of ADI also comprises austenite and ferrite (in the form of bainitic ferrite), but with graphite nodules in the matrix. The market of ADI is extremely large. Their attractive properties make them desirable not only for the manufacture of existing components with improved performance but also for competing with other materials in new applications. Advantages of ADI include high strength, ductility, wear resistance, toughness, better machinability, high damping capacity and reduced weight in comparison with forge steel. ADI has been widely used for engineering components such as 
gears, crankshaft, vehicle components, sprockets, and cutting tools. The matrix of ADI can withstand a certain amount of deformation before fracture during tensile and impact testing. However, the graphite nodules in the matrix cannot deform and hence are barriers to matrix deformation, which give rise to crack initiation. The crack propagation and the fracture mode of ADI are influenced by the orientation of bainitic ferrite needles with respect to the load direction and also by the presence of carbide particles inside the needles or at interfaces.

\section{EXPERIMENTAL PROCEDURE}

The tensile and impact test specimens of standard dimensions (as per ASTM) were machined out of Ni-Mo ductile iron casting (in the shape of cylindrical bar). The chemical composition (wt \%) is shown in Table 1.

Table 1. Nominal chemical composition (wt \%) of Ni-Mo Ductile Iron casting.

\begin{tabular}{|l|l|l|l|l|l|l|l|l|}
\hline $\mathrm{C}$ & $\mathrm{Si}$ & $\mathrm{Ni}$ & $\mathrm{Mo}$ & $\mathrm{Mn}$ & $\mathrm{Mg}$ & $\mathrm{P}$ & $\mathrm{S}$ & $\mathrm{Fe}$ \\
\hline 3.43 & 3.02 & 1.16 & 0.43 & 0.21 & 0.12 & 0.016 & 0.007 & balance \\
\hline
\end{tabular}

Subsequently these specimens were annealed at $720^{\circ} \mathrm{C}$ for $4 \mathrm{hrs}$ to homogenize the structure and to achieve uniform distribution of alloying elements. Figure 1 shows the microstructure of NiMo ductile iron after annealing.

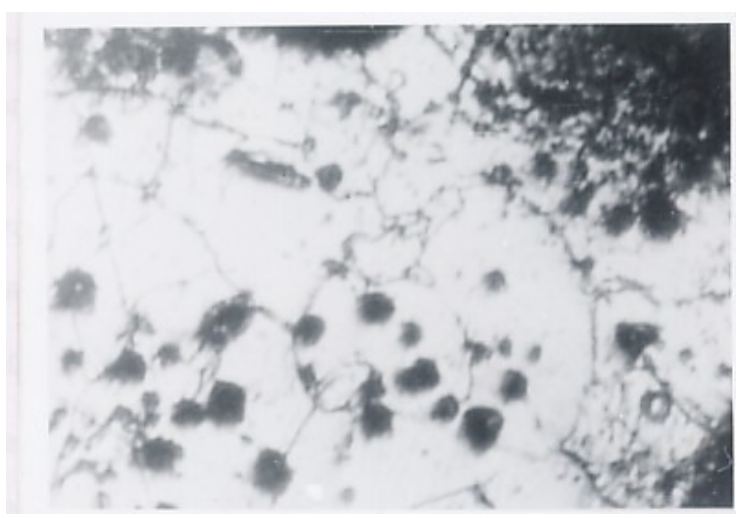

Figure 1. Ni-Mo Ductile Iron annealed at $720^{\circ} \mathrm{C}$ for $4 \mathrm{hrs}$

After annealing, all the specimens were austenitized at $900^{\circ} \mathrm{C}$ for $1 \mathrm{hr}$ and then austempered at different temperatures in a salt bath. Table 2 indicates the designation of the specimens as per the austempering temperature. The composition (wt \%) of salt bath is shown in Table 3.

Table 2. Designation of specimen under study.

\begin{tabular}{|c|c|}
\hline Specimen & Designation \\
\hline Austempered at $270^{\circ} \mathrm{C}$ for $1 \mathrm{hr}$. & $\mathrm{A}-1$ \\
\hline Austempered at $330^{\circ} \mathrm{C}$ for $1 \mathrm{hr}$. & $\mathrm{A}-2$ \\
\hline Austempered at $380^{\circ} \mathrm{C}$ for $1 \mathrm{hr}$. & $\mathrm{A}-3$ \\
\hline
\end{tabular}


Table 3. Composition (wt \%) of salt bath.

\begin{tabular}{|c|c|c|}
\hline $\mathrm{KNO}_{3}$ & $\mathrm{NaNO}_{2}$ & $\mathrm{NaNO}_{3}$ \\
\hline 40 & 55 & 05 \\
\hline
\end{tabular}

All the specimens austempered at different temperatures were then fractured under tensile and impact loading. The fractured pieces were stored in plastic bags before fractography, in order to prevent any chemical or mechanical damage to them.

The fractured surfaces were analyzed by Scanning Electron Microscope (SEM) to obtain fractographs at various locations. For fractomicrography, the specimens were sectioned in the direction perpendicular to the fractured surface, and then the specimens were polished. Subsequently the samples were etched in Nital $\left(97 \mathrm{ml} \mathrm{CH}_{3} \mathrm{OH}, 3 \mathrm{ml}\right.$ nitric acid). After polishing and etching the specimens were observed under SEM and fractomicrographs were taken in order to view the crack propagation path.

\section{OBSERVATIONS}

\subsection{Fractography}

Visual, with Optical Microscope, SEM and TEM observations of as fractured surfaces, is termed as Fractography. The effect of microstructure has been observed on the fractured surface appearance i.e. fractography. Figure 2 and 3 show the fractures surface appearance for the specimen A-1 broken in impact and tensile test respectively. The dimpled surface is observed. These dimples indicate that the fracture may have occurred by the phenomenon called void coalescence i.e. separation of the material internally, forming voids which then join to develop the fracture surface. The shallow dimples can be seen at various locations, which indicate high strength \& low ductility of the material $[2,3]$.

The fractographs of specimen A-2, broken in impact test and tensile test are shown in Figures 4 and 5 respectively. These fractographs shows the dimples at various locations which indicate the fracture may have occurred by void coalescence. The dimples are deep as compared to A-1 specimen, which indicate low strength and more ductility $[2,3]$.

The fractographs of specimen A-3, broken in impact test and tensile test are shown in Figures 6 and 7 respectively. These fractographs shows signs of cleavage as well as of void coalescence. The fractographs show river like pattern as well as dimples at various locations. This indicate that the fracture my have occurred by the mixed phenomenon i.e. quasi cleavage fracture mechanism [4]. According to which, the fracture may have occurred by cleavage at some foreign particle subsequently separated from the matrix by void coalescence. 


\subsection{Fractomicrographv}

Fractography gives information about the nature of fracture whereas the fractomicrography is the study of the surface, which is being cut perpendicular to fractured surface. After sectioning and mounting, the fractured specimens were analyzed by SEM in order to determine the crack initiation and propagation, graphite nodule shape, size, distribution and matrix structure. Fractomicrographs of specimens A-1, A-2 and A-3 are shown in Figures 10, 11 and 12 respectively.

\subsection{Matrix Structure}

The matrix of ADI is a complex mixture of bainitic ferrite and austenite, where austenite is the basic phase. On austempering at $250-330^{\circ} \mathrm{C}$, the matrix of ADI comprises the banitic-ferrite needles with carbide particles inside them and the rest is austenitic. Whereas austempering at 330 - $450^{\circ} \mathrm{C}$, the matrix of ADI observed to consist bainitic-ferrite needles without carbide particles and carbon rich / stabilized austenite, as carbon diffuses to austenite the basic phase [5].

Several bainitic ferrite needles or plate- lets have the same orientation, forming a cluster of bainitic ferrite needles or platelets. Each cluster has a particular orientation, as shown in Figure 8.

Under uniaxial external load the orientation relationship between bainitic ferrite needles and the applied load direction can be classified into three types: -

(i) The longitudinal direction of cluster of bainitic ferrite needles is parallel to the loading direction 'P', as shown in Figure 9(a).

(ii) The longitudinal direction of a cluster of bainitic ferrite needles is perpendicular to the loading direction 'P', as shown in Figure 9(b).

(iii) The longitudinal direction of a cluster of bainitic ferrite makes angle ' $\theta$ ' with the loading direction 'P', as shown in Figure 9(c).

Most of the clusters of bainitic ferrite needles belong to category as shown in Figure 9(c), but with different angles.

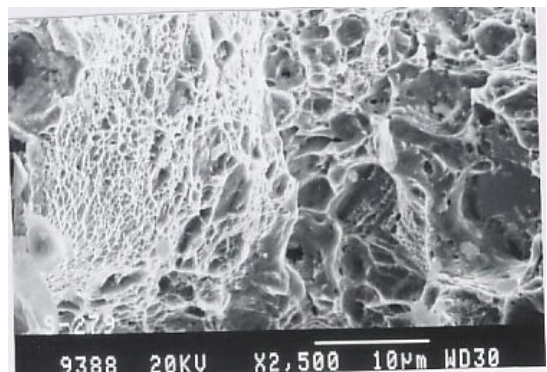

Figure 2: Fractographs of specimen austempered at $270^{\circ} \mathrm{C}$ for $1 \mathrm{hr}$. and broken in Impact test.

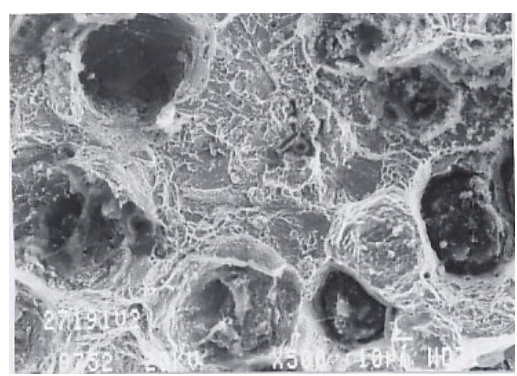

Figure 3: Fractographs of specimen austempered at $270^{\circ} \mathrm{C}$ for $1 \mathrm{hr}$. and broken in Tensile test. 


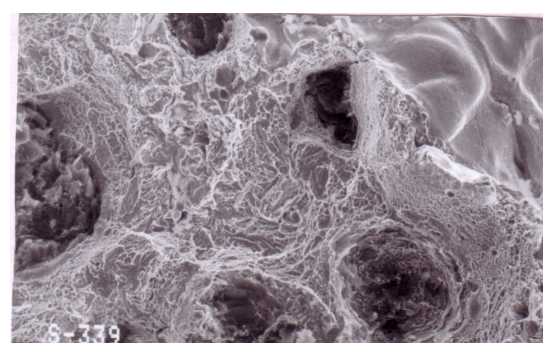

Figure 4: Fractographs of specimen austempered at $330^{\circ} \mathrm{C}$ for $1 \mathrm{hr}$. and broken in Impact test.

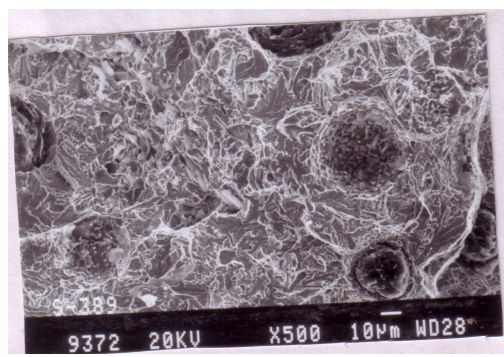

Figure 6: Fractographs of specimen austempered at $380^{\circ} \mathrm{C}$ for $1 \mathrm{hr}$. and broken in Impact test.

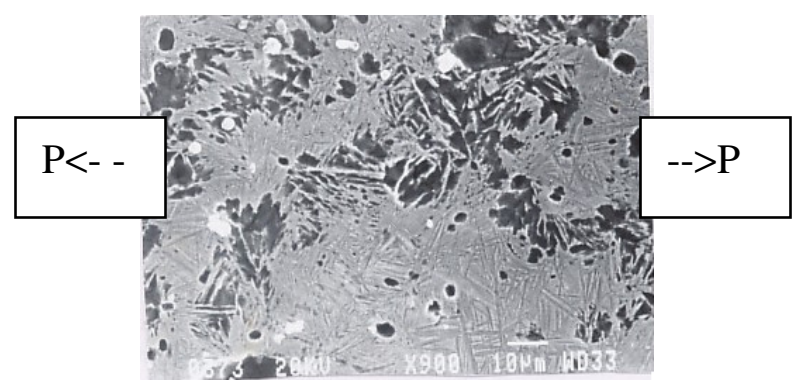

Figure 8: The orientation of clusters of bainite ferrite needles with applied load direction "P."

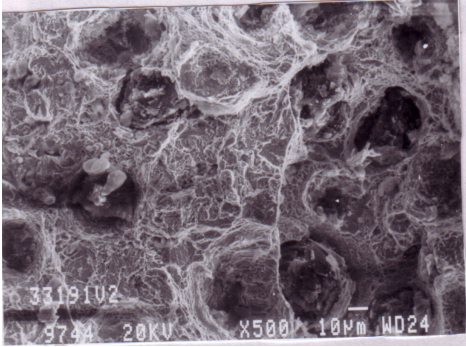

Figure 5: Fractographs of specimen austempered at $330^{\circ} \mathrm{C}$ for $1 \mathrm{hr}$. and broken in Tensile test.

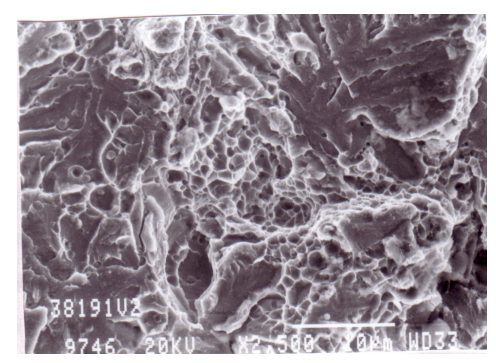

Figure 7: Fractographs of specimen austempered at $380^{\circ} \mathrm{C}$ for $1 \mathrm{hr}$. and broken in Tensile test.

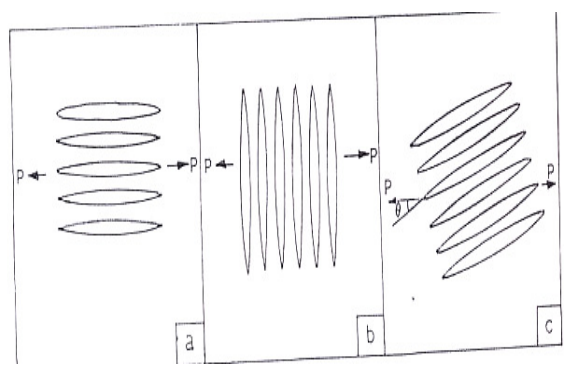

Figure 9: Systematic simplified diagram showing the possible orientation relationship between bainitic ferrite needles with applied load direction "P." 
Vol.7, No.4

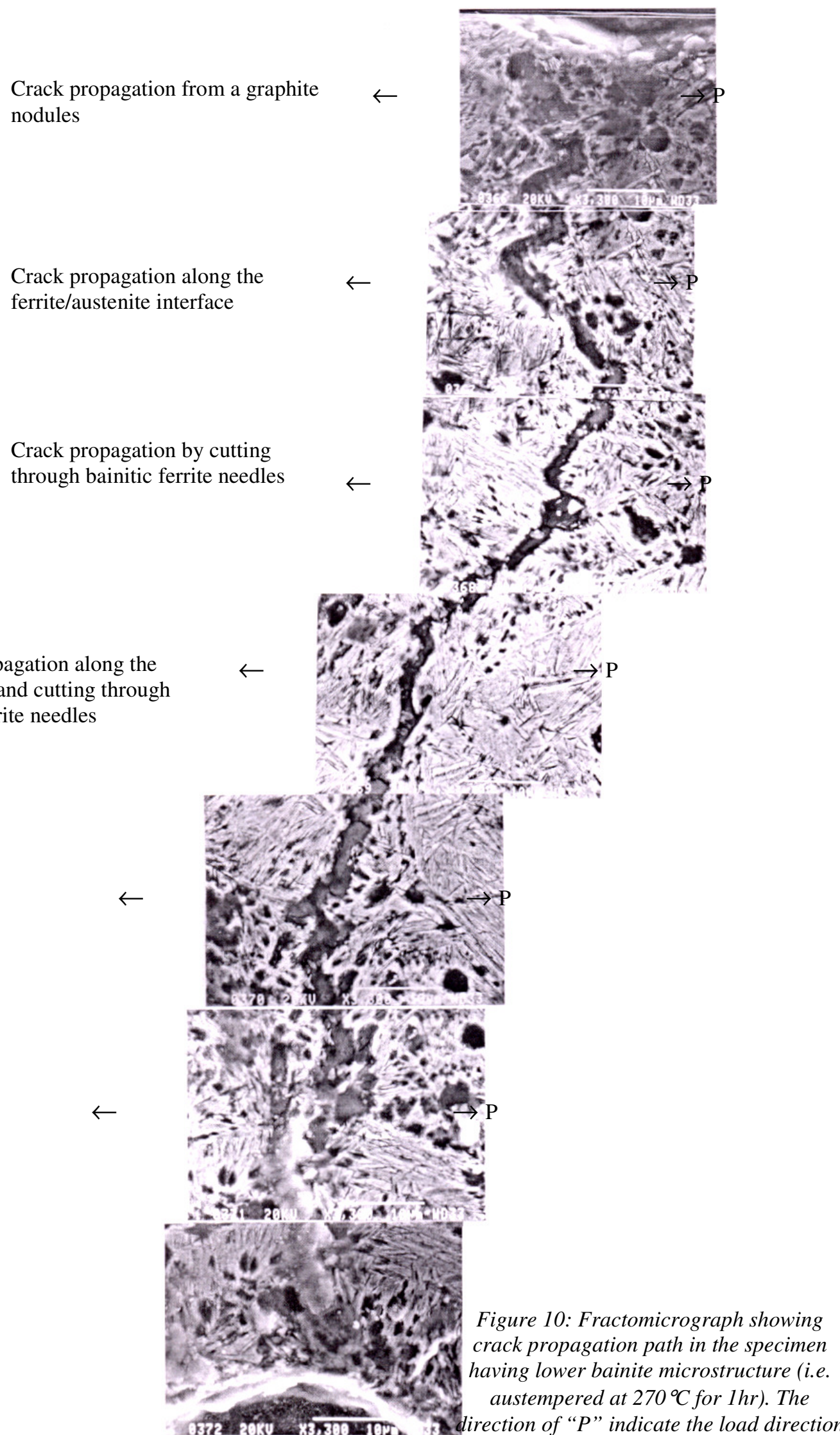

Crack propagation along the interfaces and cutting through

banitic ferrite needles

Crack propagation from a graphite

Crack propagation along the ferrite/austenite interface

Crack propagation by cutting through bainitic ferrite needles 


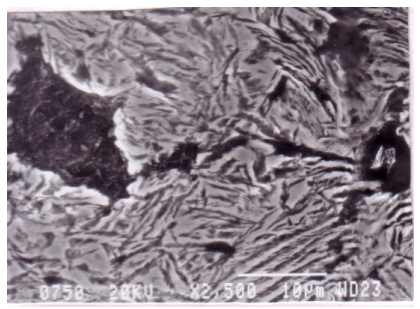

Figure 11:Fractomicrograph showing crack Initiation \& propagation in the specimen austempered at $330^{\circ} \mathrm{C}$ for $1 \mathrm{hr}$.

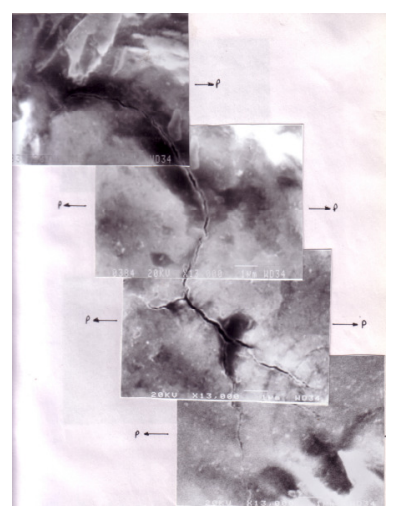

Figure 12: Fractomicrograph showing crack initiation at second phase paricle and propagation in the specimen austempered at $380^{\circ} \mathrm{C}$ for $1 \mathrm{hr}$.

\section{DISCUSSION}

Graphite nodules being discontinuities in the ADI matrix, give rise to much higher stresses around the graphite nodules during elastic deformation [6], and hence causes crack initiation at graphite / matrix interface.

For a structure similar to Figure 9 (b), the bainitic ferrite, austenite and the interfaces of ferrite/austenite will undergo similar external tensile stress. Atomic mismatch at ferrite/austenite interface decreases the tensile stress bearing capacity as compared to bainitic ferrite and austenite individually. As a result, the cracks, which originate from the graphite nodule, usually propagate along the interfaces of ferrite/austenite as indicated in Figure 10. For a structure similar to Figure 9(a) the bainitic ferrite and austenite will deform with load. As austenite has better ductility than banitic ferrite needles, thus can sustain more deformation [1]. So banitic ferrite needles will break first. The austenite deforms even after the fracture of the bainitic ferrite needles. This crack will proceed by cutting the bainitic ferrite needles.

For the most common bainitic ferrite needles structure, the crack take the easiest way to propagate, as is observed in Figure 10. The crack propagates along the interfaces of bainitic ferrite/austenite when angle between the applied load direction \& longitudinal direction of cluster is greater than $45^{\circ}$ and sometimes cut through the needles when angle is less then $45^{\circ}$.

For microstructure corresponding to the specimen A-1, which is lower bainite, carbide particles appear in the bainitic ferrite needles, which act as barrier to ferrite slip. The carbide is hardest and brittle as compared to ferrite and austenite in the matrix of ADI. There is high stress concentration around carbide particles, during deformation under load. So the bainitic ferrite 
needles having carbide particles inside them facilitate the crack to pass through bainitic ferrite needles or platelets [1], as observed in Figure 10. This creates opportunities for cracks to select an easy way to propagate. Also the carbide particles deflect the path of crack propagation. This results in the shallow dimpled fractured surface (as observed in figures: $2 \& 3$ ), which is due to high strength of the material [3].

For microstructure corresponding to the specimen A-2, crack initiation and propagation is shown in Figure 11. The microstructure consists of lower bainite (which consist of bainitic ferrite needles with carbide particles) and retained austenite. The dimples appeared deeper then A-1, which indicate this material is more ductile. The crack is initiated at graphite/matrix interface and propagates along bainitic ferrite needles/austenite interfaces or cut through ferrite needles, depending upon the orientation relationship of bainitic ferrite needles with applied load direction. For the microstructure corresponding to specimen A-3, the ADI consist of bainitic ferrite needles without carbide and high carbon stabilized austenite i.e. upper bainite is the microstructure. Upper bainite has lower strength then lower bainite microstructure, as ferrite is the softest structure. Figures 6 and 7 (showing the signs of cleavage i.e. river like pattern as well of void coalescences with dimpled structure at some locations) give indication of Quasi-cleavage fracture in the specimen A-3, which is supported by the Figure 12. This shows that the crack is initiated at second phase particle, which is hard \& brittle as compared to the matrix of ADI (which is soft \& comparatively ductile). So brittle \& cleavage fracture has occurred on the second phase particle, then separation of connecting material by void coalescence. Figure 12 show the path of propagation of crack.

According to observations the cracks are originating from graphite nodules in ADI. The easiest propagation paths for cracks are the interfaces between ferrite and austenite, because of atomic mismatch at the ferrite/austenite interfaces. The orientation of a cluster of bainitic ferrite needles and the presence of precipitated carbide in the matrix can influence the crack path. However, the orientation of the longitudinal direction of banitic ferrite needles is random and does not influence the fracture mode of ADI. Precipitated carbides in the matrix of ADI do not significantly influence the fracture characteristic of ADI. In order to analyze the crack propagation path, Fan et al. [6] have explained the crack propagation with the help of a model as shown in Fig.13. The same model is verified in our study, in which two clusters of banitic ferrite needles between two graphite nodules, one nearly parallel to applied load direction and the other nearly perpendicular to the applied load direction can be assumed. The effect of precipitated carbide on the crack propagation path and the fracture mode of ADI can be explained with a model as shown in Figure 13 [6]. 


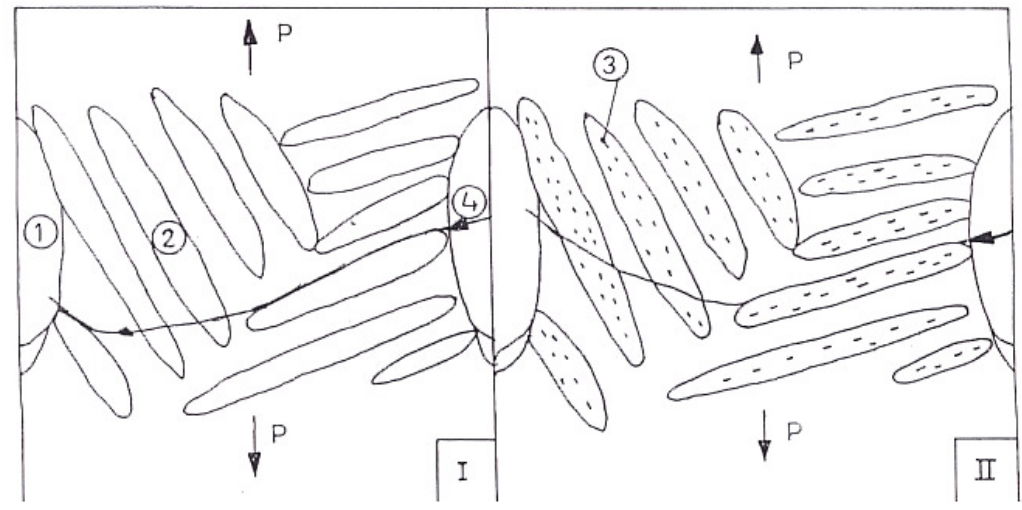

Figure 13. Two models of crack propagation in ADI [5].

Model shows:

Micro voids at graphite -matrix interfaces: -1

Bainitic ferrite needles: -2

Carbide particles in bainitic ferrite needles: -3

Possible crack path: -4

Model (I) in Figure 13 shows no carbide appear in the ADI matrix crack often pass along the ferrite/austenite interfaces for which the needles have greater angle than $45^{\circ}$ with the applied load direction. However, if the longitudinal direction of the cluster of bainitic ferrite needles tends to be parallel to the loading direction, cracks may cut through the ferrite needles (as ferrite is softest microstructure) \& austenite. In this case the fracture mode should be ductile, but due to presence of second phase particles the fracture mode is Quasicleavage as explained earlier.

Model (II) in Figure 13 show carbide in the bainitic ferrite needles or platelets, which act as barriers to ferrite slip, results in higher stress around carbide particles [6]. Large number of stress concentration locations in the needles creates particles, which further creates more opportunities for crack to pass through needles or platelets. As the carbide particles are harder so undergoes fracture without deformation and also deflect the crack path. This creates opportunity for crack to select an easy way to propagate. This result has further been supported as the fractography shows fracture in ductile mode.

Figure 13 gives just one of the main possible propagation paths of the crack. Although we cannot predict the particular propagation path, the observed results can help us understand and develop the appropriate microstructure of ADI.

\section{CONCLUSIONS}

The following conclusions can be drawn from the above study

1. Crack always originates from graphite nodules in ADI.

2. The easiest path of propagation of a crack is along the austenite/ ferrite interfaces due to atomic mismatch. 
3. The longitudinal direction of bainitic ferrite needles can be parallel, perpendicular, or inclined at angle ' $\theta$ ' with the load direction.

4. The propagation path of a crack in ADI depends upon the orientation relationship of bainitic ferrite needles with the applied load direction.

5. The fracture mode in lower bainite structure is ductile mode and the fractographs shows shallow dimpled structure, which indicates the high strength of lower bainite microstructure of ADI.

6. The fracture mode in upper bainite microstructure is Quassi cleavage or mixed mechanism i.e. the fracture firstly occurs by cleavage then separation of material by void coalescence. The fracture of second phase particle occurs by cleavage due to lack of ductility and of the matrix by void coalescence (plastic deformation).

7. Carbide particles in bainitic ferrite needles promote the passage of cracks through the ferrite needle, but do not significantly influence the fracture mode of ADI.

\section{REFERENCES}

[1] R.J Warrick "Application of Ductile Iron Castings". ASM Technical reports system no. 7645.

[2] Calangels and Heiser: Metallurgical Failure: A Wiley-Interscience publications.

[3] J.C Morrison, "What's' in a name-nickel and ductile iron". Technical paper in Indian Foundry Journal, 1998, Vol. 44(12).

[4] Ashok Chaudhary and Charlie R. Brooks "Metallurgical Failure Analysis," McGraw Hill publisher.

[5] Ray Elliot: Cast Iron Technology, Jaico publishing house.

[6] Z.Fan and R.E Smallman (1994) "Some observations of Austempered Ductile Iron". Scripta Metallurgica et Materials journal, Vol.31 (2), 1994 